\section{SEAT BELT USAGE PATTERN IN A DEVELOPING COUNTRY: SRI LANKA, WHICH IS ABOUT TO IMPLEMENT NEW REGULATIONS}

R W M A L Rajapaksha*, K G V Kumbukgolle, S D Dharmaratne Correspondence: Faculty of Medicine, University of Peradeniya, Sri Lanka, No 63/17, First Lane off, Sri Pushpadana Mawatha, Kandy, Sri Lanka

10.1136/ip.2010.029215.869

Background Road Traffic Accidents (RTAs) account for more than 1500 mortalities every year in Sri Lanka (SL). Although pedestrian fatalities have decreased, a recent increase in driver and passenger fatalities has been observed. The SL jurisdiction is exploring the possibility of implementing legislations to necessitate the use of seat belts.

Methodology This is a cross sectional observational study carried out in Kandy, the second capital of SL. Vehicles entering the city from all the major entrances from 06:00 to 12:00 h were surveyed. The observations were recorded by two independent observers and analysed using SPSS version 13.

Results A total of 20066 Vehicles were included in the study. The overall prevalence of seatbelt use is $10.87 \%$. The vehicle type significantly $(\mathrm{p}<0.001)$ affected seatbelt use, with highest prevalence seen in passengers in cars $(17.62 \%)$ and lowest in vans $(1.84 \%)$. Seatbelt use was significantly high during rush hours $(p<0.05)$. Statistically there was an influence on the usage of SB by one front seat passenger on the other $(\mathrm{p}<0.001)$.

Discussion When compared to developed countries seatbelt use is minimal in SL. Thus seatbelt use needs to be made more popular. More research is needed to identify patterns of seatbelt use and to determine what makes people not to use seatbelts. We suggest implementation of new legislations as well as launching public awareness programs. 